\title{
Research and Practice of Online and Offline Hybrid Teaching of Virtualization Technology Course in Higher Vocational Colleges
}

\author{
Ting Chen ${ }^{*}$, Haiyan Liu \\ School of Computer \& Communication Engineering Beijing Information Technology College, Beijing, China \\ *Corresponding author. Email: chent@bitc.edu.cn
}

\begin{abstract}
Virtualization technology course is not only a basic course of cloud computing technology, but also a core course of computer specialty. At present, cloud computing, big data and other technologies are developing rapidly, and virtualization technology talents are urgently needed, at the same time, it also puts forward higher requirements for the teaching mode of virtualization technology. This paper discusses the teaching mode of virtualization technology, Based on the characteristics of Vocational College Students, The online and offline teaching mode is adopted, The transformation from "Teacher-centered " to "student-centered" has gradually shifted from "what to teach" to "what to learn", and the teaching effect is good.
\end{abstract}

Keywords: Online and Offline, Mixed Teaching Mode, Virtualization Technology, Cloud Computing.

\section{INTRODUCTION}

Virtualization course in higher vocational colleges is a professional core course of computer specialty. As a new technology in recent years, virtualization technology can promote the agility, flexibility and scalability of IT industry, quickly occupy the market and generate revenue; it can reduce the cost of capital, operation and maintenance, product research and development and achievement transformation, improve the efficiency of enterprise, accelerate the speed of application and resource allocation, simplify the management of data center and improve the system Stability, business continuity, and disaster recovery capabilities to minimize or eliminate downtime. Through the study of virtualization technology, students will better understand the concept of virtualization technology and the virtual thinking of dealing with and solving problems, further strengthen the market-oriented understanding and practical application ability of virtualization technology, improve the deployment of virtualization platform and technical operation and maintenance, so as to achieve the purpose of promoting practice and production by theory.

\section{CURRICULUM DESIGN IDEAS}

The design idea of this course is based on the characteristics of vocational college students, employment factors and product characteristics, combined with the social survey of cloud computing configuration and management requirements, from the platform concept, design, construction, interpretation and other aspects, to understand the VMware vSphere virtualization architecture, VMware Workstation and the use of VMware vSphere products as the goal, to develop curriculum teaching solutions. Taking the construction of VMware vSphere private cloud platform as the main line, the course adopts the strategies of case analysis and decomposition to gradually solve the problems of cloud computing, virtualization and virtualization principles from the simple to the deep[1]. Through the teaching and teaching of this course, students can further master the virtualization related or extended knowledge, including VMware esxi installation configuration and application, VMware vCenter server application, virtual machine real-time migration, virtual switch configuration, vSphere storage configuration, VMware vCenter converter application, vSphere virtual machine backup and recovery, vSphere resource management and other virtualization related or extended knowledge. 


\section{RESEARCH ON TEACHING METHODS}

With the explosive development of information technology, education and teaching methods are also undergoing major changes. The classroom no longer inherits the former "teacher-centered" teaching method. In the teaching process, this course adheres to the concept of "teacher-centered" to "student-centered", and gradually develops a new teaching situation from "what to learn".

Take this course as an example: the teaching content, classroom form, teacher role form, students' learning form, curriculum evaluation system and so on have different degrees and targeted adjustments or changes, as shown in Figure 1.

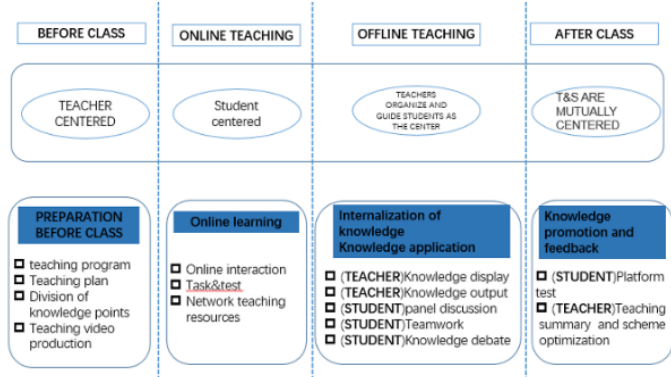

Figure 1 Online and offline hybrid teaching mode

\subsection{The Change of Teaching Content}

On the determination of teaching content, this course is no longer simply based on the syllabus or curriculum standards, but more on the characteristics of Vocational College Students' skill needs, superimposed on the social and technical talent demand and other factors, and focuses more on the improvement of students' application, innovation and learning ability[2].For example, although there are many manufacturers of virtualization technology, only a few companies have the most mature products. For example, THE HALSIGNS, the earliest virtualization software research and development company in China, windows, which took the lead in introducing virtualization technology into X86 platform, and Microsoft Hyper-V, which has been involved in the virtualization market since Server2008, and so on. Finally, the industry-leading and most reliable virtualization platform VMware vSphere is selected to build and learn the private cloud platform.

In the process of adapting to higher vocational colleges and the teaching in the past, due to the limitation of equipment and system, there have been varying degrees of challenges in this course. After improvement and optimization, the equipment hardware has been upgraded, teaching methods have been adjusted, and the platform system selection has been more accurate, more flexible teaching activities, the teaching process is no longer carried out in groups, and each student is faced with hardware, system and problems independently, analyze and develop solutions independently, independently complete all aspects of the course, such as platform construction, test the correctness and stability of the solution, and make targeted error improvement[3]. The whole process of open thinking and learning is more suitable for students to master the logic of skills, facilitate the further improvement of the whole and details, so as to achieve the cultivation of comprehensive quality and basic ability.

\subsection{The Change of Classroom Form}

First of all, with the construction of the information environment, based on the emergence of intelligent classrooms and online learning platforms such as the Internet of things, multi screen interactive technology, learning analysis technology, cloud computing, etc., the classroom form also needs to be changed[4]. This course has changed from traditional face-to-face classroom to multi open online classroom, using ICVE education platform, offline hybrid teaching mode, carry out threedimensional, open, sharing, full interactive teaching.

The online and offline hybrid teaching mode is divided into three stages:

First stage preheating. According to the goal and ability orientation, with the help of intelligent vocational education platform, the teaching content is enriched and filled, including course background, application scope, development trend, technical core, learning skills and other preheating materials. Learners can log in to the platform through the client and view learning courseware such as PPT and mooc, and can also learn all contents related to the course by searching[5]. Through this link, learners can basically understand the overall situation of the course, learning difficulties and key points, and master the basic knowledge of the course.

Second stage consolidation. In the consolidation stage, it is necessary to improve teaching skills and requirements, according to the principles of problembased and classified guidance, carry out teaching with pertinence, the goal is to teach students according to their aptitude, solve problems and improve teaching quality and efficiency, it mainly adopts the strategy of "problem normalization"[6], sorting out problems, one of the same kind, demonstration method and task driven method were adopted, carry out classified teaching, let learners learn and Practice, Improve while thinking, at the same time, we should guide learners to gradually release their enthusiasm for learning and further enhance their learning initiative, master the theoretical knowledge and improve the practical operation skills at the same time,it is mainly to stimulate students' endogenous motivation and improve their learning ability.

The third stage evaluation. After the self-assessment, learners can log in to the smart vocational education platform to complete the discussion, questions and other 
links according to their own situation. The main purpose of this stage is to understand the learners' mastery and understanding of the teaching content, it is really necessary to count and make clear the situation of the teaching objects[7], so as to accurately take measures to solve the weak links and difficult problems, learners can choose homework or test according to their own situation.

In the whole teaching process, we always adopt the "student-centered" teaching mode of sharing, opening and full interaction, any difficulty and key content can be interacted, communicated and discussed at any time without obstacles between teachers and students, the goal is the whole process of "student-centered" teaching mode.

\subsection{The Change of Teacher's Role}

The teacher is no longer the master of teaching and classroom, and the "Teacher centered" knowledge transfer is turning to help students learn. In the traditional course teaching driven by teaching, teachers will unconsciously pay more attention to the theoretical knowledge, focus on sermon and self, attach importance to students' mastery of textbook knowledge, and ignore learners' inner and active consciousness. This course focuses more on role and learner initiative. According to the talent training goal orientation and syllabus, this course builds the contents of this course on the intelligent vocational education platform, and defines the course guidance and learning objectives. Teachers will carefully select and prepare teaching materials, learning materials, reference materials in the platform, learners can be prepared, purposeful in advance, familiar with the relevant content of the course; In the teaching process, through discussion, communication, questioning, practice and observation, the interaction is convenient for learners to self-examine, learn and improve, and it is also convenient for teachers to monitor the teaching effect in real time, which provides more reference and case support for the implementation of follow-up teaching links; In the environment other than teaching, learners can choose homework and test after class to achieve the interaction between "teaching" and "learning" at any time, and form a good "teaching" and "learning" mutual promotion. The whole process is student-centered. The teacher's more role is to accompany, guide, guide and assist in learning. To some extent, it is a student's learning aid rather than a single teacher[8].

In addition, in the teaching process, the teachers implement the simulation conversion for the virtualization project, and the VMware Workstation Pro virtual machine replaces the real physical server, which meets the requirements of simulation practice under the condition of saving education and teaching resources, and carries out simulation practice without obstacles, so as to achieve the purpose of applying theory, observing results, improving and improving. In order to facilitate fragmented learning, the course is equipped with video recording and operation, and can scan QR code to watch learning at any time.

\subsection{The Change of Students' Learning Pattern}

With the students' learning environment from classroom to digital, and then to intelligent. For example, the emergence of online learning platform, mobile learning platform, online and offline hybrid learning and other new ways promote the continuous change of students' learning form[9], gradually from the traditional class standardized learning to the interactive communication between teachers and students and human-computer interactive autonomous learning. Learners are changing from passive learning to active thinking and selective learning. In this course, students take the initiative to warm up and preview before class, and study by themselves with questions. In the process, students are guided to learn actively by means of question answering and discussion. At present, the new teaching method has played a very positive role, and achieved a good effect of flexible learning, timely interaction and solid grasp. In the process of setting up this course, teachers assist students, pay attention to inspiration and guidance, give full play to the initiative and creativity of learners. At the same time, different practice links are designed according to the learners' progress, personality characteristics and learning rules[10], for example, for students who like to study, after completing the basic experiment, students can be encouraged to design their own experimental objectives, and teachers can observe and real-time observe the whole process Counseling, mainly to give advice, give questions, guide students to summarize the experiment, innovation.

\subsection{The Change of Evaluation System}

The traditional evaluation system is mainly based on students' written examination results. Although it can achieve the purpose of assessment, there are still many deficiencies, such as single assessment method, solidified knowledge level, inadequate assessment basis, and so on, which may lead to the trend of "high score but low ability". In the new form of education, the basis of students' learning evaluation has been expanded. Written examination results, usual performance, self-evaluation, students' mutual evaluation, teacher's comments, question and answer discussion and extracurricular group scores can be included in the evaluation system to comprehensively evaluate students' learning and comprehensive quality development. The diversified curriculum evaluation system can make the assessment more flexible, let the learners' ability get more comprehensive evaluation, so as to mobilize students' learning enthusiasm and endogenous motivation, and finally achieve the goal of improving teaching effect[11]. 


\section{CONCLUSION}

This paper analyzes the teaching method of "virtualization technology" under the new form of education. Through the practical observation of the application of this method in this course, it is easier for students to have a systematic and comprehensive understanding of the virtualization technology, and master the theoretical basis and operational skills necessary for the virtualization platform more efficiently and quickly. In this paper, the teaching of "virtualization technology" implements the overall thinking of Higher Vocational Colleges oriented to application-oriented talents training, and the teaching concept of "studentcentered" runs through it. The teaching system constructed provides an effective reference for future teaching and personnel training, popularizes the teaching method guided by "student-centered", popularizes the "virtualization technology" course and even the technical courses of higher vocational colleges It's very important to teach.

\section{ACKNOWLEDGMENTS}

This work is supported by grants from Teaching Reform project of Vocational Education of Beijing Municipal Education Commission (No. 2018-139).

\section{REFERENCES}

[1] Mengtao Huang, Liangu Ma, "MS-Office Teaching exploration of advanced applied micro course," On industry and science and technology,vol.17,no.1, pp.149-150,2018.

[2] Haiyan Liu, Xiaomin Liu, Ting Chen, Yi Liu. Research Overview of the Informative Teaching Approach Under cloud computing Environment. 2020 International Conference on Education Elearning and Social Scienc ,pp.7-11,2020

[3] Cuimiao Zhu, "Research on the construction of higher vocational software talents' innovation ability training system,” office automation,vol.24,no.16, pp.38-40,2019.

[4] Simo Sun, "On the teaching mode of cloud computing and big data processing," Intelligence,vol.26, pp.151,2016.

[5] Jianying Wei, "Research on teaching mode of cloud computing and big data processing," Science and technology innovation guide,vol.36, pp.213214,2016.

[6] Jinghai Bao, Xiaozhu Zhou and Donghong Fan, "Research on building virtual network laboratory based on VMWare," Computer technology and development,vol.6,pp.242-245,2016.
[7] Xiangyu Bian, "Application of virtual machine technology in Computer Laboratory,” Journal of Changchun University of Technology,vol.6,pp.5557,2016 .

[8] Chunjiao Chen," Setting up computer software system maintenance experiment environment with VMWare," Optical disc technology,vol.4,pp.5657,2009 .

[9] Feng Lv, Hong Yang," Construction of virtual network computer laboratory based on VMWare," Computer programming skills and maintenance,vol 16,pp.76-77,2009.

[10] Yingzhuang Li, Nan Wang and Xianyi Li, “Design and implementation of cloud platform based on open stack,” Journal of Wuhan University,vol.12,no.06,pp.101-106,2017.

[11]Ye Zhou, Yong Li and Fang Wang,” Network experiment platform technology based on open flow," Journal of Tsinghua University,vol.11,no.52,pp.236-237,2018 